САХИБГОРЯЕВ Вадим Хасанович - доктор философских наук, профессор кафедры теории и истории государства и права Северо-Восточного государственного университета (685000, Россия, 2. Магадан, ул. Портовая, 13; vadim-50@rambler.ru)

КОТОВ Сергей Владимирович - доктор политических наук, профессор кафедры технологии и профессионально-педагогического образования Южного федерального университета (344065, Россия, 2. Ростов-на-Дону, пер. Днепровский, 116; cat0016@yandex.ru)

ПОНЕДЕЛКОВ Александр Васильевич - доктор политических наук, профессор кафедры политологии и этнополитики Южно-Российского института управления - филиала Российской академии народного хозяйства и государственной службы при Президенте РФ (344082, Россия, г. Ростов-наДону, ул. Пушкинская, 70; ponedelkov@uriu.ranepa.ru)

\title{
К ВОПРОСУ О ЮСТИФИКАЦИИ ФАШИЗМА
}

Аннотация. Фашизм был и остается одной из актуальных тем современного обществознания. В последнее время наметились процессы, направленные на оправдание фашизма, развивающиеся в основном на постсоветском пространстве. Статья посвящена исследованию новых его проявлений, неожиданных форм его бытия в современных социокультурных обстоятельствах. Речь идет о системной, практически официальной фашизации общества, когда обстоятельства и факты пересмотра исторического процесса в пользу национально-оборонительных доктрин зачастую приводят к оправданию национальных фашистских движений, их героизации, а также к частичному их возрождению. Предлагается идея о существовании официального фашизма, или ретрофашизма, тиражирующего предложенную гитлеровской пропагандой культурно-историческую концепцию о так называемой культурной миссии Европы. Выявляются основные характеристики этого феномена.

Ключевые слова: фашизм, постсоветское пространство, фашизация общества

$\mathrm{C}^{\mathrm{o}}$ овременные процессы, происходящие в Европе, да и во всем мире, лишний раз убеждают в том, что фашизм по-прежнему остается одной из актуальных тем, исследования которой должны носить перманентный характер. И не только потому, что мы до сих пор переживаем последствия этого явления, преодоленного человечеством более полувека назад, но и потому, что мы вновь и вновь сталкиваемся с новыми его проявлениями, порой совершенно неожиданными флуктуациями его развития.

Фашизм как социальное явление с определенной социальной базой не возникает и не может возникнуть спонтанно. Он всегда есть следствие каких-то предшествующих процессов, оказывающих сильное воздействие на национальное сознание, побуждающих к пересмотру нормативных (общепринятых, устоявшихся) ценностей, культурных и исторических воззрений. Часто или почти всегда фашизм есть результат какого-либо «заговора молчания», скрытой поддержки, поощрения, особенно если он рассматривается как некий инструмент при достижении политических целей. Любая внешняя поддержка, явное или скрытое поощрение всегда или почти всегда приводят к бурному прогрессу и нарастанию популярности этого феномена.

Безусловно, фашизм может существовать и длительное время существовал как атомарное, группускулярное явление, увлечение единиц, горстки маргиналов, террористов, но в этом случае он никогда не оказывал серьезного влияния на крупные социокультурные процессы, не становится частью официальной политики. (Группускулярность - термин, по-видимому, введенный одним из авторитетных исследователей фашизма и неофашизма Р. Гриффином. Он характеризует количественное и качественное состояние неофашистских организаций Европы второй половины прошлого столетия и означает разрозненность, немногочисленность, полуподпольный характер существования и деятельности неофашистских организаций.) В этой ипостаси фашизм существовал 
на протяжении всего постфашистского периода истории, иначе говоря, второй половины XX столетия. Именно в данный период возник феномен так называемого неофашизма, т.е. бытия фашизма на современной почве, когда осужденный и отвергнутый мировым сообществом, самой культурой фашизм совершенствовал и адаптировал к меняющемуся миру основные свои доктрины и постулаты, оправдывал собственную контркультурную сущность.

В последнее время все отчетливей высвечиваются контуры более грозного и деструктивного образа фашизма, что лишний раз указывает на необходимость его дальнейших исследований.

Речь идет о системной, практически официальной фашизации общества, когда обстоятельства и факты пересмотра исторического процесса в пользу национально-оборонительных доктрин зачастую приводят к оправданию национальных фашистских движений, их героизации, а также к частичному их возрождению. Так, стремление официальных властей некоторых западных соседей России придать Великой Отечественной войне характер антисталинской освободительной борьбы зачастую оборачивается героизацией фашистов-коллаборационистов 40-х годов XX столетия. Распад Советского Союза на почти два десятка суверенных государств, часть которых до сих пор остаются непризнанными государствами-образованиями, положил начало новой антироссийской линии международных отношений. Она, эта линия, характеризуется не только риторикой дефицита суверенности, но и во многом представляет собой манифестацию радикальных политических взглядов и концепций, частью которых является фашизм. Вновь, как и в эпоху «холодной войны», находясь в перманентном поиске средств и методов причинения любого урона «противнику», Запад демонстрирует завидное хладнокровие, наблюдая, как фашизм выходит из «подворотни истории», и использует его антироссийский потенциал. Таким образом, политический крах фашизма, его полное военное поражение не стали причиной гибели фашизма как такового. Также и и идейное, и духовное осуждение фашизма не является причиной отказа от него как от приемлемого вектора общественного развития, что, собственно, и выводит теоретическое осмысление фашизма на новый уровень, поскольку в поле исследования внедряются все новые аспекты его бытия. Так поучение Марка Аврелия Антонина: «Выверни и взгляни, каково оно и каким становится старое, больное, потасканное» [Антонин 1985: 45] обретает практический смысл.

Наблюдение за политическими процессами, происходящими на постсоветском пространстве, позволяет говорить о новой флуктуации фашизма. Его, по-видимому, следует отнести к формам проявления неофашизма, исходя из известной классификации В. Виппермана [Випперман 2000], предполагающей, что некое мемориальное состояние фашизма, его рецидивы возможны. Вместе с тем это уже не тот вид неофашизма, с которым хорошо познакомилась Европа в 50-80-х гг. прошлого века, когда идеи реванша, расового превосходства и симпатии к политическим режимам фашистских Италии и Германии сплачивали отдельные группы молодых маргиналов, питающих надежду на то, что «теоремы» фашизма не исчерпали себя и имеют право на жизнь. Не зря их называли неофашистами. Тот вид фашизма, о котором мы говорим сейчас, имеет признаки вполне самостоятельного общественного явления, поскольку не только плотно связан с официальными властями целого ряда государств Европы, но и вновь рассматривается как панацея, как едва ли не единственный способ обретения «долгожданной» национальной независимости, препятствием для которой является так называемая имперская политика России.

Данный тип неофашизма вырастает из весьма масштабного процесса переоценки и пересмотра концепций исторического прошлого, когда вдруг обре- 
тенная государственная независимость рассматривается не как общий процесс распада Советского Союза, а многовековой опыт непримиримой борьбы, в которой хрононимы «царизм» и «эпоха сталинизма» занимают центральное место. Этот тип неофашизма можно назвать официальным неофашизмом, и он напрямую связан с таким новым явлением, как юстификация фашизма. Сентенция: «Никто не мог защитить нас от сталинизма, кроме Гитлера» постепенно превратилась в самостоятельную идеологическую программу, имеющую массу поклонников и сочувствующих.

По-видимому, он, этот тип фашизма, берет свое начало в процессах идеологической институционализации независимости в странах Прибалтики еще в 90-х годах XX столетия, а оформляется окончательно в канун 60-й годовщины победы над фашизмом, когда «парламенты Латвии, Литвы и Эстонии, а также Балтийская ассамблея выступили с требованиями новых официальных извинений России за “оккупацию Прибалтики”» [Крысин 2007: 546]. История официального неофашизма коротка. Как форма заблуждения, он появляется в крайне расплывчатых контурах сразу после распада СССР. Еще в 1990-х гг. на него смотрели как на один из негативных сопутствующих демократизации феноменов. Его связывали скорее с пробуждением национальных архетипов, с естественным стремлением найти надежную замену идеологии социализма. Заметим, что идеи фашизма нашли сочувствующих и в России. Однако российский неофашизм так и не приобрел широкого распространения и официальной поддержки и остался по большей части уголовным преступлением, чего не скажешь о некоторых государствах бывшего СССР. Там поднялась волна ностальгии по «забытым героям» Второй мировой войны. Там стали искренне верить в то, что под нацистским мундиром бьется сердце истинного патриота.

Уже в начале XXI столетия официальный неофашизм оформляется в устойчивую систему политико-культурных взглядов и широко используется как мощный инструмент размежевания между Российской Федерацией и частью бывших ее союзников. Начиная с этого периода неофашизм врастает в ткань официальной политики государств Балтии, Украины, отчасти - Грузии и Молдовы как идеология отрицания прошлого. В 2015-2016 гг. процесс юстификации фашизма (под юстификацией мы понимаем стремление оправдать, придать законный характер общественному явлению) обрел наиболее масштабные формы на Украине, что повлекло за собой не только фашизацию общества «сверху», но и массовое развитие и деятельность фашиствующих группускул практически по всей территории Украины. Фашиствующие молодчики стали популярными, они проникли в парламентские структуры, возглавили общественно-политические движения, открыто взялись за оружие и во многом повторили бесславную боевую практику своих «духовных отцов» и предшественников на Донбассе и в других регионах Украины, где требовалось участие на все готовых карателей.

Политически идея юстификации фашизма базируется на утверждении о перманентной борьбе украинского народа против «русской», или «российской» агрессии, «русского» и «российского» присутствия в культуре, экономике, политике. История Украины рисуется и формируется как непрерывная череда событий, объединенных противофактической идеей освобождения от чего-то крайне грозного и докучливого, насыщенной мифами, подменяющими факты. Идеологически процесс юстификации находится в зависимости от стандартного мифа любого фашизма - мифа о расовом превосходстве. «Когда мы смотрим на нацистскую идеологию, мы видим, в частности, что это расизм, который и делает фашизм фашизмом» [Harun 2002: 151]. Так, миф о глубоких доисторических корнях «великого и таинственного» народа созидателей - «укров» выполняет двоякую служебную функцию. Во-первых, этот миф аргументирует 
все актуальные идеологемы современной украинской политики, доходчиво поясняет, почему и когда появилась «высшая раса» и в чем ее преимущество, а во-вторых, он является водоразделом, отделяющим современного украинца от всех остальных представителей славянских народов, возвышающим его над ними. В современной украинской идеологии во многом господствует риторика именно этнического, этнокультурного смыслового поля.

Показательно, что именно это явление - «оживление» мифа расы - описывал в свое время один из идеологов нацизма Альфред Розенберг, когда говорил об «оживающей крови», процессе становления так называемого расового сознания. В частности, он писал: «Современность и прошлое появляются внезапно в новом свете, а для будущего вытекает новая миссия» [Розенберг 1998: 3]. В этом будущем Розенберг уже не видел никакого иного вида социальной борьбы или социального противостояния (например, борьбы классов, политических партий), кроме расового.

Миф о расе положил начало процессу обособления украинской культуры, отделению всего «украинского» от «русского», «российского». Данный процесс является существенным признаком фашизации массового сознания, о котором также позитивно высказывался Розенберг. Он писал по этому поводу: «Мы видели, что за религиозными, моральными и художественными ценностями стоят расово обусловленные народы, как в результате безудержных смешений все истинные ценности в конце концов уничтожаются, народная индивидуальность исчезает в расовом хаосе с тем, чтобы продолжать влачить жалкое существование в виде нетворческой мешанины или, служа новой, сильной расовой воле, подчиняя ее духовно и материально» [Розенберг 1998: 351]. Так возникает оскорбительный и унизительный миф о «ватниках», «колорадах» - угрюмых, нелюдимых пропойцах, тунеядцах, агрессивных завистниках, оккупантах, паразитирующих на украинской культуре, который совершенно четко указывает на глубокие системные отличия между братскими народами.

Сам процесс юстификации фашизма, или оправдание фашизма, придание ему черт позитивного и конструктивного историко-культурного, исторически оправданного явления есть феномен фашизации общества «сверху», когда официальная идеология и политика открыто принимают фашизм. Однако филофашистские настроения (филофашистский - сочувствующий фашизму, элементам его идеологии и практики, отчасти - подражающий фашизму) первых лиц государства в сочетании с разворачивающимися бурными событиями, часть которых не поддаются контролю, неизбежно способствуют развитию неофашистских движений с широкой массовой базой, что мы, собственно, и наблюдаем в современной Украине.

Любопытным является то, что фашизм фактически служит одним из инструментов геополитического противостояния России и Запада. В этой связи попытка войти в европейскую семью народов буквально предполагает необходимость отмежевания от России. Особо показателен в этом смысле пример современной Украины, стран Балтии, где филофашистские настроения наиболее сильны и оказывают существенное влияние на процессы и мотивы формирования государственной политики. Избрав европейский путь развития, предполагающий сближение с Европой, Украина проводит интенсивный курс на размежевание с Российской Федерацией. Разрушаются экономические, социальные, политические, культурные, духовные связи, формируется национальный корпус мифов о самобытности «украинца», величии культуры Украины и одновременно - о дикости и отсталости России. Инициированы системные процессы «укрофикации», т.е. приведения в соответствие социокультурного уклада с некими противофактическими установками мифа. При этом про- 
цесс «укрофикации» весьма напоминает политику «нордификации» фашистской Германии, проводимую в середине 30-х гг. ХХ в., хорошо описанный В. Клемперером [Клемперер 1998: 240]. Как отмечал У. Эко, говоря об архетипах фашизма, «в основе ур-фашистской психологии заложена одержимость идеей заговора... Лучший способ сосредоточить аудиторию на заговоре - использовать пружины ксенофобии» [Эко 2003: 21]. Показательным представляется и сам способ формирования образа врага, когда Россия рисуется одновременно и могущественным оккупантом, с которым ведется затяжная война, и обреченным на поражение конкурентом, не заслуживающим особого внимания. У. Эко отмечал данный прием узко фашистской пропаганды, называя его «колебанием риторических струн», когда «враги рисуются в одно и то же время как и чересчур сильные, так и чересчур слабые» [Эко 2003: 21].

Признавая, что фашизм является европейским, т.е. западным, феноменом, позволим себе небольшое отступление, чтобы определить наше понимание проблемы.

Часто, применяя понятие «Запад», мы устанавливаем приблизительный водораздел, разграничивающий некие географические, культурные и духовные пространства планеты. В отличие от А. Зиновьева, который определял «западное общество» именно как «суверенные страны, а не их части и не их объединения» [Зиновьев 2007: 23], мы, определяя данный термин, имеем в виду группу государственных сообществ, обладающую общей идентичностью, ценности которой распространены от образа гуманиста Швейцера до образа завоевателя Кортеса. Это гигантское духовное пространство, простирающееся от героического самоотречения до идеальной алчности, объединенное термином «либерализм». Именно этот термин чаще всего употребляется и является общепринятым, когда речь идет о необходимости систематизировать, обобщить всевозможные представления о том, что мы часто называем «обществом золотого миллиарда», «передовыми странами», «открытым обществом», «западным миром», «западной цивилизацией» и т.д., и т.п.

Вводя в научный оборот понятие «западнизм» как целостный социальный феномен, А. Зиновьев говорит о пространной совокупности, включающей «и капитализм, и демократию, и социализм (коммунизм), и прочие общественные явления» [Зиновьев 2007: 23]. А. Зиновьев отмечает при этом, что Запад «теперь обозначает не просто определенное множество стран, но стран, являющихся воплощением западнизма» [Зиновьев 2007: 24]. Данное обстоятельство является определяющим, поскольку делает возможным рассматривать западнизм как общество 2-го порядка, включающее в себя все присягнувшие ему суверенитеты, в т.ч. и те, которые только стремятся войти в западное сообщество.

Это, в свою очередь, способствует формированию реалистических представлений о том, что западный ансамбль суверенитетов, сплоченный западными ценностями, выступает единым фронтом в развивающемся социокультурном и политическом взаимодействии с иными культурными мирами. Весьма часто данное взаимодействие оборачивается конкуренцией и даже противостоянием. Похоже, что одним из сопутствующих продуктов данной конкуренции (противостояния) стало системное пробуждение филофашистских настроений в части государств Восточной Европы, стремящихся к всесторонней интеграции с Западом.

Это абсолютно новое явление. Речь идет о ретрофашизме, полном принятии его классических и радикальных символов, их врастании в структуры формирующихся национальных идеологий - феномене, находящемся вне самой полной квалификации видов и форм фашизма, данной В. Випперманом [Випперман 2000]. Ренессанс фашизма в части современной Европы есть обращение к 
фашизму в его «чистом» виде, в фундаментальных образах и символах, когда идеи этнической, расовой «чистоты» и «полноценности» непосредственно сопряжены с политической необходимостью противостоять неотвратимой внешней угрозе.

Так фашизм обретает вторую жизнь, где существенно расширяется его тематическая роль, при которой символ старого фашизма, его персонаж строит мир, необходимый и достаточный для противостояния совершенно конкретно означенной силе. Оборонительным мифом ретрофашизма выступает топоним «Россия», сохраняющий единое содержание, невзирая на эпоху. Просторы России для мифологического героя ретрофашизма становятся утопическим пространством, полем действия, без которого весь миф теряет смысл. Так, без России нет идеи «освобождения от России», нет мифа «об угрозе для всей единой цивилизованной Европы». Ахронический смысл данному топониму придает мифологическое представление о невероятной мощи России, слиянии представлений о географическом и временном пространстве, о контррационализме, вечной агрессии и дремучей дикости «вечного тоталитаризма» России вне зависимости от ее социального уклада.

В числе ярких характеристик ретрофашизма можно выделить следующее.

1. Преодоление группускулярности [Fascism 2004]. Это связано с состоянием неофашизма, которое в свое время описали Р. Гриффин и М. Фельдман, когда он напрямую зависел от организационной формы своего существования, что объяснялось, прежде всего, официальным запретом на фашизм, когда даже некритическое упоминание о фашизме считалось крайне предосудительным. Во избежание преследований со стороны закона сочувствующие фашизму группировались в мелкие структуры, часто независимые друг от друга, и поддерживали достаточно высокий уровень конспирации. Как правило, преодоление группускулярности приводит к открытому тиражированию филофашистских идеологем и отход от поведения, предполагающего какую-либо скрытность, конспирацию. Это открытая демонстрация фашистской символики и атрибутики, энергичная националистическая риторика, вхождение фашиствующих элементов в официальные органы власти.

2. Модернизация немецко-фашистской социальной мифологии: тиражирование культурно-исторической концепции, предложенной гитлеровской пропагандой, о так называемой культурной миссии Европы, благодаря которой фашизм рассматривается как способ освобождения от большевизма или препятствования его распространению на основе эксплуатации свойства ахронии (вневременной природы лексико-семантических структур). Так, термины «большевизм» и «современная Россия» обретают взаимозаменяемый характер, когда выражения «освободиться от большевизма» или «противостоять большевизму» означают то же самое, что «освободиться от современной России» или «противостоять современной России». Принцип соответствия определенному времени таких явлений, как «большевизм» и «современная Россия», подменяется приемом ахронии - превращения данных понятий в одну из противоположностей семантической категории, единую смысловую субстанцию, где другой противоположностью может являться все, что ей оппозиционно. Так, «либерализм» и «фашизм» попадают в число родственных категорий, наполняющих единое семантическое поле, находящихся в оппозиции к «большевизму» и «современной России». Это способствует формированию представлений о России как о культурно-историческом феномене, культурной среде, культурном пространстве «неевропейского» характера, враждебного Европе и европейской культуре.

3. Сращивание идеи длительной и мучительной борьбы за независимость с идеей расового превосходства над «агрессором», полного освобождения от 
которого якобы не достигнуто. Признание факта культурной отсталости, антропологической неполноценности и даже дикости населения Российской Федерации, необходимости борьбы с якобы нарастающей новой российской геополитической угрозой идейно увязывается с хрононимом «эпоха сталинизма». Именно данное положение служит некоторым оправданием юстификации фашизма при априорном предположении, что сталинизм хуже, более деструктивен, чем фашизм. Фашизм выступает альтернативой сталинизму - не лучшей, но способствующей освобождению от сталинизма.

4. Отказ от общепринятых культурно-исторических концепций и оценок фашизма, Второй мировой войны и периода послевоенного урегулирования европейского политического порядка. Реанимация и актуализация идеи фашистской пропаганды о том, что война в Европе и война с Советским Союзом есть не что иное, как освобождение от «большевистской чумы», от вековой экспансии имперской России. В этом смысле эпоха классического и радикального фашизма оценивается как позитивный период истории, характеризующийся объединением «просвещенной Европы» против сталинизма и большевизма. Отсюда вытекает официальное признание национальными героями не только тех, кто находился на службе у фашистских оккупантов, но и лидеров и вождей национально-фашистских движений 30-40-х гг. XX в., героизация пособников фашизма.

Линия поощрения Западом филофашистского курса политических элит стран Балтии и Украины представляется как «не всегда соответствующая» западной политико-правовой культуре и практике. Правомерен вопрос: не является ли поддержка радикального национализма предвестником отказа от так называемых общеевропейских ценностей? Ведь сценарий появления и укрепления официального неофашизма почти полностью повторяет сценарий событий конца $20-\mathrm{x}$ - начала $30-\mathrm{x}$ гг. ХХ столетия в части реакции на него респектабельного либерального европейского сообщества. По-видимому, принцип: «все, что наносит какой-либо ущерб России, не может быть скверным» принят в качестве программы действий не только на Украине, но и в Европе. Во-первых, данному явлению, злонамеренно либо по недоразумению, уделяется крайне мало внимания. На это явление взирают как на часть более масштабных, существенных событий и не только не пытаются с ним бороться, но и как бы не замечают его. Во-вторых, западная культура, по-видимому, отстранилась от самоанализа и формируется лишь под влиянием идеи прогресса, когда прошлое считается окончательно пережитым, а его рецидивы представляются немыслимыми. В-третьих, господствует старый принцип: «разделяй и властвуй», при котором считается возможным оценивать любой урон конкуренту как благо. Европа вновь попадает в ситуацию, при которой внешняя угроза становится причиной какого-либо действия, плана. Процесс поступательного институционального развития Евросоюза в целом завершен. На смену ему пришли многочисленные процессы дезинтеграции, связанные с защитой национальных интересов субъектов Евросоюза, некоторые противоречия экономического развития. Экономические, политические, инфраструктурные, а порой и идеологические противоречия субъектов Евросоюза в данной ситуации решаются не только практически, но и идеологически - посредством обоснования идеи единства перед лицом мифологической угрозы. Так единая Европа вступает в стадию развития, когда принцип свободной воли, добровольного желания жить в единой семье народов уже не является цементирующим. На ведущие позиции выходит сама необходимость единства, некое принуждение. Европа попадает, таким образом, в зависимость от мощной идеологии, компонентами которой и выступают некоторые заимствования из геополитических теорий фашизма. 


\title{
Список литературы
}

Антонин Марк Аврелий. 1985. Размышления. Л.: Наука. 276 с.

Випперман В. 2000. Европейский фашизм в сравнении: 1922-1982. Новосибирск:

Сибирский хронограф. 239 с.

Зиновьев А.А. 2007. Запад. Алгоритм. М.: Эксмо. 512 с.

Клемперер В. 1998. Язык Третьего рейха: Записная книжкка филолога. М.: Прогресс-Традиция. $381 \mathrm{c.}$

Крысин М.Ю. 2007. Прибалтийский фашизм. История и современность. М.: Вече. 576 c.

Розенберг А. 1998. Миф ХХ века. Оценка духовно-интеллектуальной борьбы фигур нашего времени. Таллин. $393 \mathrm{c.}$

Эко У. 2003. Вечный фашизм. Пять эссе на темы этики. СПб. $371 \mathrm{c.}$

Fascism. Vol. V. Post-War Fascisms (ed. by R. Griffin, M. Feldman). 2004. London. $463 \mathrm{p}$.

Harun Ya. 2002. Fascism: the Bloody Ideology of Darwinism. Istanbul: Arastrima Pablishing. $241 \mathrm{p}$.

SAHIBGORYAEV Vadim Hasanovich, Dr.Sci. (Philos.), Professor of the Chair of Theory and History of State and Law, North-Eastern State University (13 Portovaya St, Magadan, Russia, 685000; vadim-50@rambler.ru)

KOTOV Sergei Vladimirovich, Dr.Sci. (Pol.Sci.), Professor of the Chair of Technology and Professional Pedagogical Education, Southern Federal University (116 Dneprovsky Lane, Rostov-on-Don, 344065, Russia; cat0016@yandex.ru) PONEDELKOV Aleksandr Vasil'evich, Dr.Sci. (Pol.Sci.), Professor of the Chair of Political Science and Ethnopolitics, South-Russian Institute of Management, Russian Presidential Academy of National Economy and Public Administration (70 Pushkinskaja St, Rostov-on-Don, Russia, 344002; ponedelkov@uriu.ranepa.ru)

\section{ON THE ISSUE OF FASCIST JUSTIFICATION}

\begin{abstract}
Fascism is one of the topical themes of modern social studies. Recently, there have been processes aimed at justifying fascism, developing mainly in the post-Soviet space. The article is devoted to the study of its new manifestations, unexpected forms of its existence in modern socio-cultural circumstances. It is a systemic, almost official fascization of society, when circumstances and facts of the revision of the historical process in favor of national defense doctrines often lead to the justification of national fascist movements, their glorification, and their partial revival. The authors suggest studying an idea of official fascism or retro-fascism, replicating the cultural-historical concept proposed by Hitler's propaganda about so-called cultural mission of Europe. The authors identify main characteristics of this phenomenon.

Keywords: fascism, post-Soviet space, fascization of society
\end{abstract}

